\title{
Seeking treatment for uncomplicated malaria: experiences from the Kintampo districts of Ghana
}

\author{
Lawrence G. Febir ${ }^{1 *}$, Kwaku Poku Asante' ${ }^{1}$ Samuel Afari-Asiedu1', Livesy N. Abokyi ${ }^{1}$, Anthony Kwarteng ${ }^{1}$, \\ Bernhards Ogutu ${ }^{3}$, Margaret Gyapong ${ }^{2}$ and Seth Owusu-Agyei ${ }^{1}$
}

\begin{abstract}
Background: Malaria accounts for many deaths and illnesses, mostly among young children and pregnant women in sub-Saharan Africa. An integrated approach is recommended to ensure effective malaria control. Socio-cultural factors continue to serve as determinants of malaria health-seeking behaviour. An INDEPTH effectiveness and safety study platform was established to unearth issues around the use of licensed and nationally recommended antimalarials in real life settings. This study reports on treatment-seeking behaviour for uncomplicated malaria among community members.

Methods: A qualitative study was conducted in the dry and rainy seasons in purposively selected communities in Kintampo north and south districts. This was based on distances to a health facility, ethnicity and availability of medicines at the sale outlets. Twenty-four focus group discussions were conducted among adult men, women care-takers of children less than 5 years and pregnant women. Ten INDEPTH interviews were also conducted among operators of medicine sale outlets and managers of health facilities. Fifty-one illnesses narrative interviews were conducted among adult men, women, women caretakers of children less than 5 years and pregnant women. Transcripts were transferred into Nvivo 8 software for data management and analysis.
\end{abstract}

Results: The artemisinin-based combinations that were commonly known and used were artesunate-amodiaquine and artemether-lumefantrine. Use of herbal preparation to treat diseases including uncomplicated malaria is rife in the communities. Drug stores were not the main source of artemisinin-based combination sales at time of the study. Monotherapies, pain killers and other medicines were purchased from these shops for malaria treatment. Dizziness, general body weakness and sleepiness were noted among respondents who used artemisinin-based combination therapy (ACT) in the past.

Conclusion: There is no clear cut trajectory for management of uncomplicated malaria in the study area. Different approaches are adopted when treating malaria. There is need for community education to influence behaviour on the management of malaria to achieve real gains from ACT use.

Keywords: Uncomplicated malaria, Experiences, Treatment

\section{Background}

Malaria is still a major cause of deaths and illnesses; it affects mostly young children and pregnant women with the highest burden in sub-Saharan Africa. It was

\footnotetext{
*Correspondence: lawrence.febir@kintampo-hrc.org

${ }^{1}$ Kintampo Health Research Centre, P. O. Box 200, Kintampo, Ghana Full list of author information is available at the end of the article
}

responsible for an estimated 482,000 deaths among children under 5 years, 3.4 billion people worldwide are at risk of malaria infection, $90 \%$ of all malaria deaths occur in sub Saharan Africa [1]. An integrated approach involving all the currently available tools is recommended. Access to treatment with effective anti-malarials need to be ensured, while also undertaking preventative measures such as targeted vector control [2]. Though some studies 
have been carried out that described factors influencing treatment-seeking for malaria, far less is known about the relative weight given to these factors in different settings. Sociocultural research on malaria health-seeking behaviour recognizes issues influencing choice of provider for treatment $[3,4]$. Other factors such as ethnicity also influences treatment-seeking with certain ethnic groups being much more reliant on traditional self-medication remedies $[5,6]$. These sociocultural determinants of malaria health-seeking behaviour are often local and may change with time [7-9].

Product development Phase I, II and III randomized, controlled clinical trials have been well-supported and have established the initial safety and efficacy of such products when delivered under tightly monitored conditions. However, there is very little experience with the effectiveness and safety evaluation of medicines deployed on a large scale within African health systems. An effectiveness and safety platform was established by the INDEPTH network to document the safety and effectiveness of artemisinin-based combination therapy (ACT) in real-life settings. This platform, INDEPTH Effectiveness and Safety Study (INESS) was established with the aim of minimizing the time gap between post-regulatory licensure and adoption of new anti-malarials by providing timely safety and effectiveness data from endemic countries to guide national and global policies and practices.

Qualitative data was collected as part of this INESS initiative with the aim of identifying factors that influence community members' ability to seek and receive appropriate treatment for malaria in Kintampo in the middle part of Ghana.

\section{Methods}

\section{Study area}

Data was collected from respondents in the Kintampo north and south districts in Ghana, between November 2009 and July 2010. The two districts are located within the forest-savannah transitional ecological zone in the Brong-Ahafo Region, covering an area of $7162 \mathrm{~km}^{2}$. Malaria transmission is high with 269 infective bites per person per year with an all year round parasite prevalence of about $50 \%$ among children $<5$ years of age [10]. The area's resident population was 134,970 in 2009 [11]. Community members are predominantly farmers. Data were collected to coincide with the dry season (i.e. December 2009 to March 2010), a period that corresponds with low malaria transmission, and collection was repeated during the rainy season (i.e. April 2010 and October 2010), which corresponds to the high malaria transmission season.

The majority of inhabitants in this area initiate treatment for some ailments at home, then continue to the
Licensed Chemical Shops and may finally end up in a public health facility if their illness do not resolve [12]. There are two public hospitals, twelve health centres/ clinics and thirty community-based health planning and services (CHPS) compounds. These facilities provide health service delivery to urban as well as to the majority of deprived rural poor community members in the study area.

\section{Data collection methods}

Four rural communities located in the south and west of the Kintampo Districts were purposively selected for data collection based on availability/unavailability of health facilities as well as ethnic balance involving the two dominant tribes in the study area.

\section{Focus group discussions (FGDs)}

Twenty-four FGDs were conducted separately, eight among adult men, eight among pregnant women and eight among caretakers of children less than 5 years of age in their respective communities. Compounds having potential discussants were randomly selected using the Kintampo Health and Demographic Surveillance System (KHDSS) database [11]. The selection criteria were: adults between 18 and 80 years who lived in the purposively selected communities. The potential discussants were identified in their various homes through the assistance of community opinion leaders. Respondents of different ages were put together to form a group of discussants. Males and females were put in separate groups for each discussion session. Discussions were held in twi (the widely spoken local dialect) all FGDs were held in either a church or an open space. The discussions were facilitated by a moderator using an interview guide that was made up of predetermined questions and themes. Other related emerging issues were also discussed. Notes on responses and other non-verbal communications were also taken by a notestaker. Each session was digitally recorded; this was complemented with the notes taken by the notes-taker during the results write up process. Each discussion session also lasted for about an hour. Interview sessions were brought an end when the moderator had exhausted all questions on the interview guide and other emerging issues. The FGDs assessed the care-seeking behaviour for malaria, knowledge of malaria treatment and malaria treatments received at the health facilities and retail medicines sector. The perception of community members on how malaria treatment works general knowledge and experiences with new anti-malarial drugs and their experiences with ACT, more specifically artesunate-amodiaquine. ACT contraindications were explored; their perceptions of the most effective and the less effective malaria treatment were also explored. A study team member moderated each interview session 
while the responses were recorded by a second person to aid transcription and analysis. Interview sessions lasted between one and one and half hours and involved discussants who numbered between eight and twelve.

\section{In-depth interviews (IDIs)}

Ten in-depth interviews (IDIs) were conducted by a study team member, among health centre workers (4- 2 in Kintampo North and South Districts respectively) and drug store operators (6- All in Kintampo South District). All the drug store operators and in-charges of health centres in both districts were interviewed. There were no drug stores in study communities in Kintampo North District as at the time of the study). Interviews among drug/chemical store operators were conducted in the premises where the medicines are sold to clients. Interviews were conducted when attendance was very low to avoid interruption by potential clients. Each session was digitally recorded; this was complemented by the notes taken by the notestaker during the results write- up process. Each interview session lasted for about thirty minutes to an hour. The health centre workers interviews centred on their hours of operation at the various health facilities and the type of services they provide, category of health personnel working in the facility; malaria diagnosis and treatment practices; patients preference for medicines and the reason(s) for their preference; perceptions on efficacy of medicines and their reasons for that perception; the types medicines patients request for, types of anti-malarial drugs in retail outlets and patients knowledge of malaria. In the case of medicine shop operators, interviews centred on the hours of operation at the various medicine shops, the services provided, anti-malarials including ACT available in the shop for sale, the type of ACT stocked and their source of supply; knowledge of malaria, clients medicine preference and the reason(s) for such preference, providers medicine preference and the reasons for this preference.

\section{Illness narrative interview (INI)}

The illness narrative interview was performed using an interview guide on the last episode of malaria, sources and sequence of treatment, preference for any particular type of treatment, perceived side effects and experiences with such treatments, perceptions about efficacious medicines and reasons for preference of such medicines. All persons who were ill with a fever in the past 2 weeks prior to the day of interview were eligible to be interviewed. Caretakers responded on behalf of their under 5 years old children. INIs lasted between 10 and $25 \mathrm{~min}$. All INIs were digitally recorded by a moderator who also made summaries and notes of non-verbal communication. Once the questions on the guide and other emerging issues are exhausted by the moderator, the interview session comes to an end.
A total of fifty-one INIs were conducted, 12 among men, 16 among women, 16 among women caretakers of children less than 5 years of age and 7 among pregnant women. Respondents were individuals in the study area that were part of the KHDSS database and have had an episode of malaria in the 2 weeks preceding the day of the illness narrative interview. Caretakers of children less than 5 years of age responded for their children who were qualified to be interviewed. To select respondents, a list of compounds was randomly generated from the KHDSS database. This was followed by a search through the compounds for any member defined above who qualified for this interview. Those found were screened to ascertain eligibility and to ensure that not more than one category of respondent is selected from a compound. Respondents were interviewed on the sequence and types of treatment sought for that episode of malaria, the content of their consultation with health providers, the type of malaria treatment provided by health care providers, the perceptions of malaria treatment received, their opinions about best malaria medicines and malaria prevention and any malaria related issues in the communities.

\section{Data management and analyses}

Data from FGDs, IDIs and INIs were recorded using a digital recorder, transcribed verbatim, checked for completeness and accuracy; audio-recordings were vetted to match transcripts by the study team leader. The data were coded independently by two persons. To ensure intercoder agreement and reliability, $10 \%$ of the transcripts were coded and this was followed with a debriefing session to discuss the level of agreement. The level of agreement between the independent coders was always above $90 \%$. Responses were subsequently grouped and categorized according to the themes under the study objectives and emerging themes as determined by the data using NVIVO version 8 qualitative data management software. Data were thematically analysed to identify themes that best addressed study's objectives and related emerging themes. Responses that best describe the various themes served as quotes to support the findings. Table 1 gives details on how the data was analysed.

\section{Ethical issues}

Approval to conduct the INESS study was granted by the ethics committees of Ghana Health Service and the Kintampo Health Research Centre. Discussants and participants in FGDs, IDIs and INIs were taken through an informed consent process; in which they either agreed or disagreed to be part of discussion/interview. Community entry involved explaining the study to chiefs and key community opinion leaders. This was followed by preparatory meetings with community opinion leaders and 
Table 1 How data collected in December 2009-October 2010 was analyzed

\begin{tabular}{ll}
\hline 1 & Two moderators coded data independently \\
2 & $10 \%$ of data were independently coded and compared to ensure inter coder reliability and an agreement then reached on a coding tree \\
3 & Themes were identified in advance and emerging themes were derived from data \\
4 & Nvivo version 8 software was used for data management \\
5 & Quotations were presented to illustrate themes. All quotes attributable to participants were anonimized \\
7 & Major themes were clearly presented in the findings \\
7 & There were descriptions of diverse cases and discussion of major themes \\
\hline
\end{tabular}

other stakeholders from these communities to explain details of INESS and the objectives of the qualitative component, what their roles are and would be in the data collection processes.

\section{Results}

\section{Characteristics of respondents}

Table 2 gives a summary of the characteristics of respondents.

\section{Community knowledge of ACT and availability of ACT at the community level}

The artemisinin-based combinations that were commonly known and used by community members are artesunate-amodiaquine and artemether-lumefantrine. Artesunate-amodiaquine was commonly referred to as the "Yellow and white" tablets by respondents:

when I took that white and yellow, I only felt weak. That is the only thing I saw, apart from that, I did not experience any other side effect (FGD: Man)

He gave me drugs; one is white and the other is yellow. He also gave me blood tonic and para. (INI: Woman)

In some of the communities accessing ACT was a challenge. ACT was not available for community members to buy in time of need.

The white and yellow isn't available at the drug store (FGD, pregnant woman)
Some community members mentioned only "amodiaquine" when they actually meant artesunateamodiaquine. Artesunate-amodiaquine, which is the first-line drug for the treatment of uncomplicated malaria is the ACT usually dispensed at the health facilities. Artemether-lumefantrine is dispensed by some health facilities in the study area.

As said earlier, amodiaquine is very good for the people of Amoma [referring to artesunate-amodiaquine] (FGD, Man)

The medicine sale outlets (Drug stores) do not normally dispense ACT. Community members therefore purchase monotherapies, pain killers and other drugs from them to treat malaria.

That is what I told you earlier that we do not sell drugs like artesunate-amodiaquine but we sell drugs like Quick Action [Caffein, Ephederine HCL, paracetamol] and efpac [acetylsalicylic acid, caffeine, paracetamol] which are always advertised on radio so if the person comes and we have to give him Efpac or Quick action, we tell him to take it three times a day (IDI, drug shop operator)

For malaria medicines we have malafan [sulfadoxine pyrimethamine, Amodiaquine syrup; first we have the tablet but now we do not get it that much and Kinaquin 442 [Chloroquine]. (IDI, Drug shop operator)

Table 2 Characteristics of respondents

\begin{tabular}{|c|c|c|c|c|}
\hline \multirow[t]{2}{*}{ Data collection method } & \multicolumn{2}{|c|}{$\begin{array}{l}\text { Age ranges } \\
\text { of participants }\end{array}$} & \multicolumn{2}{|l|}{ Education level of participants } \\
\hline & Men & Women & Men & Women \\
\hline Focus Group discussion & $25-80$ & $18-45$ & From no education to tertiary & From no education to senior high school \\
\hline INDEPTH Interview & $35-52$ & $53-56$ & From middle School leaving certificate to senior high school & $\begin{array}{l}\text { From middle school leaving certificate to } \\
\text { Midwifery }\end{array}$ \\
\hline Illness narrative interview & $36-60$ & $18-55$ & $\begin{array}{l}\text { From no education- to general certificate of Education } \\
\text { (ordinary level) }\end{array}$ & From no education to senior high school \\
\hline
\end{tabular}




\section{Experience with ACT}

Respondents reported several experiences when they used ACT. Respondents generally held that, ACT make them weak and as such make them feel sleepy a lot and that one needs a long rest when taking ACT.

The drug causes you to sleep so when you take it you need to rest for about two to three hours else you become very weak (INI, woman)

Also respondents at INI sessions commonly mentioned that ACT can cause dizziness if a patient takes it without eating

Personally I feel dizzy when I take artesunate-amodiaquine without eating (INI: Man)

Others also mentioned that ACT cause them to vomit.

I came home just around this time. He asked me to take some of the drug so I took it. I also took some around one o'clock in the afternoon; he gave me three and asked me to try and take all in three days. So I took two in the morning and two in the afternoon; whilst taking it I felt the scent of the drug in my nose but I tried to swallow it. After taking it I felt like vomiting but I tried as much as possible to control it but I couldn't so I had to vomit; that day I vomited a lot. (INI; pregnant woman)

Again, respondents mentioned that for ACT to work well and to prevent body weakness the patient must eat before taking it, apart from this they also mentioned the need to take the medicines as prescribed. Furthermore, respondents mentioned that ACT cause fast heart beat which will lead to some form of worry as mentioned below by respondent

...So I took two and half for two times, the moment you take the drug you feel dizzy. In about thirty minutes I felt sleepy, so I slept meaning the illness itself was cured. But with the sleep, no break, so my husband even asked whether I've taken some alcohol. (INI, Woman)

Respondents associated cure during a malaria episode with the following experiences during ACT treatment: "good sleep", "urinate very well", change in urine colour, excessive sweating, "yellow vomit", eating "very well", and reduction of a "child's temperature and chills".

When you sleep three hours after taking the drug you will sweat and when you urinate you will see the difference. Thus the colour of your urine will change. (FGD:Man)

So after taking the drug, you realize that your temperature comes down; and with the weakness, you not even able to go out to urinate. So, having taken the drug and when it begins to work, you realize you've gained some strength and you're able to move about. (FGD: Pregnant woman)

\section{Malaria health-seeking behaviour: the role of ACT}

Study participants do not adopt a single treatmentseeking pattern for uncomplicated malaria. Some participants visited health facilities immediately they felt unwell. Those diagnosed for malaria in the health facilities were readily treated with an ACT as the only drug used for malaria treatment. Other community members visited drug stores to purchase any drug they deemed appropriate for the disease suspected or mentioned their health condition to the vendor who decides on which drug (among those listed in Table 3) is most appropriate to be dispensed to cure the illness. Other community members initiated treatment with some left over drugs or start with some herbal preparations using herbs listed in Table 4. There were however, some respondents who used ACT alongside herbal preparations, whiles others used ACT for some days and switch over to any other drug or herbal preparation.

I agree with him. When you treat it traditionally and it still persists then opt for orthodox treatment in the health facility. (FGD, Man)

I think that even if the herbs will help, one has to go to the hospital first to get treatment, so that upon returning, the herbs can be used to supplement so that it will help. So the hospital is the best way to help ourselves in treating malaria (FGD, Woman)

we only pushed ground ginger into her anus but it didn't work so I bought drugs at the drug shop. it did not work either so I took her to the hospital. (IDI, caretaker of a child less than five years)

You send the patient to hospital and after that you also cut some herbs like mango leaves, lemon and the "Timforgor" [the name of a herb] that she mentioned and the lemon leaves are mixed together (FGD, Woman)

Community members who used herbal preparations used parts of plants (roots, barks and stems and leaves) as itemized in Table 4.

\section{Category of people who must not take ACT}

The following categories of people were cited by a minority of community members as the group who could not take ACT: pregnant women, children less than 12 years 
Table 3 List of medicines sold to patients in the study area who present with fever/malaria at chemical stores: December 2009-October 2010

\begin{tabular}{ll}
\hline Type of anti-malarial monotherapy & Other medicines \\
\hline Malafan (Sulfadoxine pyrimethamine) & Paracetamol \\
Kinaquin 442 (Chloroquine) & Oral Rehydration Salt \\
Chloroquine & Glucose \\
Camoquine (Amodiaquine) & Cafenol (Acetaminophen, Caf- \\
& feine) \\
Amodiaquine syrup & Vitamin B complex \\
Amodiaquine suspension & Quick Action (Caffein Ephedrine \\
& $H C L$, paracetamol) \\
\hline
\end{tabular}

of age, diabetic patients, anemic persons and individuals with heart problems. Community members believed that ACT works on "blood" and therefore likely to affect foetus and children who are perceived to have very little blood. The following quotation show this position

Pregnant women should not take it because from what people say the drug is powerful and melts blood so I think it is not good for them. (FGD: Man)

I said an anaemic; because the drug is powerful and works with blood so such a person should not take the drug. (FGD: Man)

These perceptions were however held by the minority of discussants upon subsequent probing.

Reasons for self-treatment, care-seeking at health facilities and chemical shops for uncomplicated malaria in the communities

Generally, participants cited different reasons why they self-treat ailments such as malaria. Key among them were lack of money to either purchase medicines at the chemical shops or pay for cost at the health facilities, unavailability of means of transport in their communities to send them to a health facility and poor roads. Self-treatment was practiced to complement treatment that they receive at health facilities or when they perceive that treatment at the health facility failed. Another reason was patronizing the purchase of medicines of drug peddlers during their home visits to convince them of the potency of their medicines. Some quotes below illustrate some reasons cited for self- treatment:

If you realized you have malaria. We have transport problems to help us get to the health facility. You pluck some leaves, boil and take them (IDI, caretaker of a child less than five years)

Supposing you get malaria and have to go to the hospital, you'll be required to pay; so if you don't have money you give up and look for some herbs (FGD, Man)

My two year old child has been affected with malaria, and I've tried several times but did not work so I'm thinking of preparing herbs, as a support to see if that can work. So I believe that one can help (FGD caretaker of a child less than five years).

The following reasons were however cited for visiting health facilities: services rendered and the availability of laboratory services in the health facilities, the use of health insurance as a mode of financing services delivered at the health facilities, proximity to health facilities and opportunity to visit and report the inability of a medicine provided at the facility to treat their disease condition, lack of knowledge of the cause of a disease condition they have been affected with as well as not getting cured after self-medication or seeking treatment at the drug store. They also cited the devastating effect of malaria and visits to health facilities is in response to calls to seek treatment at health facilities for all ailments, including malaria as some of the reasons. The quotes below illustrate some of the reasons cited for visiting health facilities:

Table 4 Table showing herbal plants used to treat uncomplicated malaria in the study area: December 2009-October 2010

\begin{tabular}{ll}
\hline Local name of plant mentioned by respondents & English name of plant \\
\hline "Duagyene-wuraa" & "Neam tree Leaves" \\
"Kashedua wuraa" & "Acacia tree Leaves" \\
"Acheamponwuraa" & "Siam weed" \\
"Amango-wuraa" & "Mango leaves" \\
"Brofrewuraa-a-awo" & "Dried pawpaw leaves" \\
"Teek-wuraa" & "Teak leaves" \\
Ankaa-twadee-wuraa & "Lime/Lemon leaves" indica \\
\hline
\end{tabular}


At the clinic, they have some machine. They will first take samples of your blood is to examine whether malaria parasites are in or not. So if it is found out that the parasites are in, you are given malaria treatment (FGD, man)

When the illness comes, I buy drugs but when it becomes very serious, I have to send the person to the health facility. (FGD, man)

The reasons cited for patronizing medicine in retail outlets (i.e. drug stores) included: distance to health facilities, if drugs given at the health facilities are perceived not to be working well, as well as drug stores being immediate and accessible for solutions to health problems and medical advice

The health facility is very far from here as a result after the day's work or when we wake up and feel body pains all over, we get some pain killer from the drug store before we look for other source of treatment (FGD, Man)

If let us say I send the child to the clinic today being Friday, I'll wait for a week to see if the child's condition does not improve, then I'll buy drugs at the store. I will not send him/her to the clinic again (FGD, caretaker of a child less than five years)

\section{Malaria diagnosis and treatment practices}

Malaria diagnosis was based on clinical symptoms presented at health centres and drugs stores. The excerpts below support this finding.

...when you look at the person and the way he is standing, thus if the person says I am feeling cold, dizzy then you realized that it is fever (IDI, Drug store operator).

We don't have a laboratory so we look at symptoms to prescribe but when we give them the treatment too they become alright (IDI, an in charge of Health Centre).

This notwithstanding health centre workers and drug store operators considerably adhere to the malaria treatment guideline for children under 5 years of age and pregnant women as revealed in the responses below.

For the under-fives, if we check and he is below the age that he cannot take the Amodiaquine and he is feverish we give para [paracetamol] and advice that they are taken to the hospital (IDI, a drug shop operator).
We do not give any pregnant woman drugs over here. At our workshops we are thought that when someone is pregnant it is only the doctor who can prescribe medicine for her so we do not sell malaria and other drugs to pregnant women (IDI, a drug shop operator).

\section{Category of staff, hours of operation and type of services provided in health centres and chemical stores}

The categories of staff at Health Centers are mainly enrolled nurses and Physician Assistants who are incharge of consultation and health service delivery. They are supported by Community Health Officers who are in charge of history taking and medicine dispensary. Chemical stores are operated by chemical sellers who have received some basic form of training in medicine dispensary from the pharmacy council of Ghana. This is what a respondent had to say about the category of staff who work at the health center.

I am a physician assistant but you know we have community health officers over there (she points to a section of the health facility). If any FP (Family planning] patient comes, they go to their [community health officer] office and I will be working at the consulting room (IDI, In-Charge, Health Center).

With regards to the hours of operation, whilst health centers operate from 8 a.m. to 5 p.m. on working days, drug shop operators work from 6 a.m. to 8 p.m. a daily on both week days and weekends. However, it is interesting to note that both health centers and drug shops operate as and when they are called upon to attend to patients/ clients as illustrated in the quote below.

I work from 8 am to $5 \mathrm{pm}$ on week days; after that when any case comes they come and call me sometimes on weekends. So I'll work for 24 h (IDI, InCharge, Health Center).

Health services provided by health centers are mainly diagnosis and treatment of uncomplicated malaria. Other services include the provision of reproductive and child health care such as family planning services, antenatal and post-natal care. Like the health centers, chemical sellers provide treatment for basic ailments based on clinical symptoms but refer children and other clients whose condition they perceive as "higher than" them to the health centers.

For the under-fives if we check and he is below the age that he cannot take the Amodiaquine and he is still feverish we give paracetamol and advice that they are taken to the hospital (IDI, drug shop operator). 
Table 5 gives a summary of category of staff, hours of operation and the type of services provided in health centers and chemical stores.

\section{Discussion}

There have been several studies on the knowledge of ACT among communities and health workers in subSaharan Africa [12-16] and their use can be successfully integrated into the malaria home management programme [13]. However a study in Nigeria [14] revealed that a significant number of community members have no knowledge of ACT, though they could have been treated with ACT. This study adequately demonstrates some level of knowledge of ACT among community members that were involved in this study. The challenge about knowledge is the ability of discussants/respondents to mention the name of the actual ACT that they mean. This call for the need for national malaria programme managers to come out with short names or abbreviated versions of names of ACT. Community members should be adequately educated on this abbreviated versions or short names to enhance its usage. Disposition related to medicine use vary among communities. They are either negative or positive. Whilst a study in Malawi recorded positive disposition about use of artemether-lumefantrine [15], this study recorded some negative experiences by community members who used Ghana's first-line malaria treatment, artesunate-amodiaquine. Some of the negative experiences were dizziness, drowsiness, "body weakness". These experiences could create perceptions that may have negative consequence for the successful implementation of health programmes, as happened in Nigeria during a polio immunization campaign [16], if not properly managed.

Experiences of patients and community level interpretation of the use of medication has the tendency to foster continuous use of such medicines or rejection. In a study to assess the barriers to malaria mass drug administration [17], it was revealed that fears of perceived side effects such as dizziness, stomach ache and the quantity of medicines that needed to be taken contributed to poor adherence. Women who intended to get pregnant refused and the state of their pregnancy also contributed to the refusals. This study recorded similar findings. Respondents indicated that they feel dizzy when they take ACT. A minority group of respondents cited specific group of people such as pregnant women children and diabetics as people who should not take ACT. This position was not corroborated by Dial et al. [17]. Though this perception was held by a minority group, it is likely that women and children who are at risk may be discouraged from taking ACT. This could lead to poor treatment outcomes. National malaria control programme managers should strengthen education on adherence to curtail this misconception. Another study [18] on adherence and uptake of ACTS in northern Ghana also did not indicate the caliber of people that must not take ACTs. In light of the effects these may have on compliance, experiences in the malaria control efforts studies have come up with some suggestions. A study in Tanzania [19] suggested incorporating local beliefs and practices surrounding use of anti-malarials into programmatic goals to significantly improve uptake malaria control interventions. In Malawi [15], caregivers deliberately altered dosing regimens of artemether-lumefantrine and dihydoartemisinin-piperaquine depending on whether they perceived the medication to be strong or weak. The study by Eving et al. [15] suggested further optimization of anti-malarial adherence among children, with the development of antimalarials with pharmacological properties that allow user-friendly administration with easy and simplified dosing schedules.

The use of herbal preparations in treatment of diseases is a well-documented phenomenon in many parts of Africa [20-24]. Ethno pharmacological studies on the use of herbal remedies for malaria in Ghana [25] concluded that the use of herbal remedies to treat malaria was a common practice. This study also documents the continual use of herbal preparations in treating malaria. Many unexpected health problems could arise if this not checked and properly managed. Sometimes, doses are not too clear to the end user, chemical composition and toxicity effects are also not clearly documented. These and other contributory factors could make end users vulnerable to other health problems that may lead to fatalities including deaths.

Treatment practices including self-medication with anti-malarials has been widely reported in many parts of Africa [26-31], reasons cited were health facilities challenges such as shortages of medicines, long waiting time, perceived quality of services, location of facilities and distance from homes, inability to pay for health care costs, and lack of freedom to choose medicines of their choice [27, 32]. Drug shops still remain one of the significant sources of anti-malarials distributed to communities [26]; though the main source of anti-malarials, the knowledge of those in-charge of the drug shops was not satisfactory when it comes to malaria case management and other diseases as previously documented [26]

Also, the findings on malaria diagnosis and treatment practices corroborates the fact that, the lack of laboratories and malaria test kits in lower health facilities are the major setback in the diagnosis and treatment of malaria in Ghana. As regards the WHO malaria treatment guidelines [33] adopted by Ghana suspected malaria cases are to be tested and confirmed before malaria drugs are 


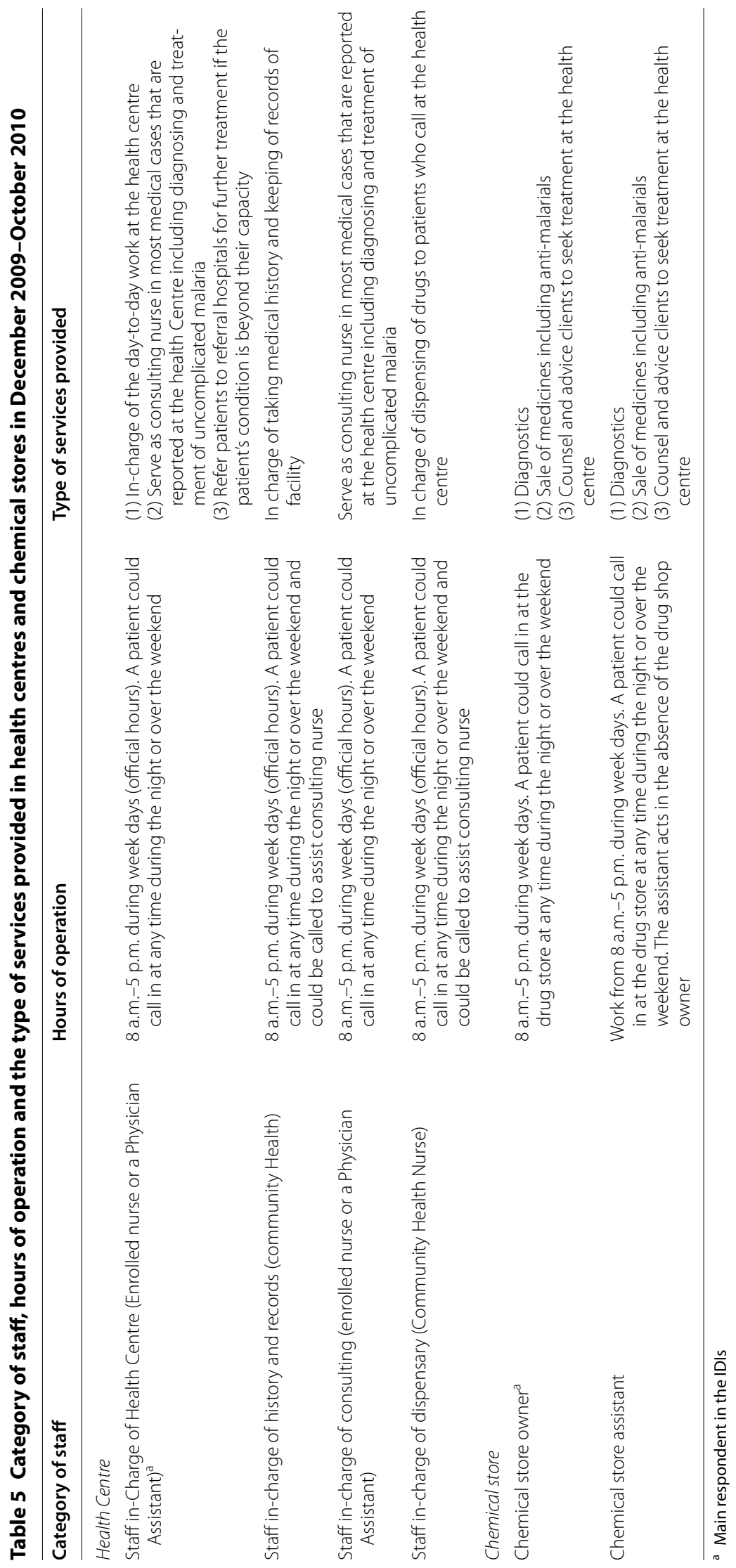


prescribed. There are efforts by the Ghana Health Services to supply malaria test kits to health centres but the supply has been erratic

The categories of health staff in rural health facilities play a major role in the health delivery process. The absence of qualified staff serves as a big disincentive to rural and deprived communities. Their continuous presence in the health facilities and how easily they are accessible contributes immensely to the timely provision of cure for ailments including uncomplicated malaria. The finding on the category of staff in health facilities in this study is in agreement with findings from a systematic review on motivation and retention of health staff in rural communities in developing countries [34]. The review emphasized that, health worker retention is therefore critical for health system performance and efforts must be put in place to ensure their motivation [34].

\section{Conclusion}

There is no clear-cut trajectory for management of uncomplicated malaria in the study area. Different approaches are adopted when treating malaria. Many factors determine how community members seek health when they are unwell. These include drug availability, sociocultural behaviour and cost. The use of herbal preparations to treat many ailments including uncomplicated malaria is very common. There is need for community education to influence behaviour on the management of malaria to achieve real gains from ACT use.

\section{Authors' contributions}

LGF analysed the data and drafted the manuscript. MG, LN, LGF, SO-A, conceived, designed and implemented the study. SA-A, LG, AK, LN KP and SO-A implemented the study and reviewed the manuscript. AK, LN, LG analysed the data and reviewed manuscript. KP, LG, MG, BO and SO-A critically reviewed the manuscript. All authors read and approved the final manuscript.

\section{Author details \\ ${ }^{1}$ Kintampo Health Research Centre, P. O. Box 200, Kintampo, Ghana. ${ }^{2}$ Dodowa Health Research Centre, P. O. Box DD1, Dodowa, Ghana. ${ }^{3}$ INDEPTH Network, Accra, Ghana.

\begin{abstract}
Acknowledgements North Municipality and Kintampo South District particularly the study participants for their participation. We also thank the field staff, computing, laboratory and administrative staff of the Kintampo Health Research Centre for the various roles they played in collecting and processing the data. We acknowledge the pivotal role of INDEPTH Network and the INESS secretariat in securing funds and coordinating the study. We also appreciate the contribution of Bill and Melinda Gates Foundation in funding this project. The team also acknowledges the role of Dr. Denise Allen Roth of the Centres for Disease Control, Atlanta USA for her role in the study.
\end{abstract} \\ The study team is most grateful to the community members of Kintampo}

\section{Competing interests}

The authors have declared that they have no competing interests.

Received: 2 June 2015 Accepted: 4 February 2016

Published online: 20 February 2016

\section{References}

1. WHO. World malaria report 2013. Geneva: World Health Organization; 2013.

2. WHO. World malaria report 2009. Geneva: World Health Organization; 2010.

3. McCombie S. Treatment seeking for malaria: a review of recent research. Soc Sci Med. 1996:43:933-45.

4. Williams HA, Jones CO. A critical review of behavioral issues related to malaria control in sub-Saharan Africa: what contributions have social scientists made? Soc Sci Med. 2004;59:501-23.

5. Mensah AO. Impact of socio-economic factors on malaria treatment seeking behaviour: analysis of provider choice and timing of treatment on southern rural Benin. London: London School of Hygiene and Tropical Medicine (University of London); 2004.

6. Saeed I, Ahmed E. Determinants of acquiring malaria among displaced people in Khartoum state, Sudan. East Mediterr Health J. 2003;9:581-92.

7. Ahorlu CK, Koram KA, Ahorlu C, De Savigny D, Weiss MG. Socio-cultural determinants of treatment delay for childhood malaria in southern Ghana. Trop Med Int Health. 2006;11:1022-31.

8. Mwenesi HA. Social science research in malaria prevention, management and control in the last two decades: an overview. Acta Trop. 2005;95:292-7.

9. Dhiman SK. Malaria control: behavioural and social aspects. DRDO Sci Spec. 2009;183-86.

10. Owusu-Agyei S, Asante KP, Adjuik M, Adjei G, Awini E, Adams M, Newton S, Dosoo D, Dery D, Agyeman-Budu A. Epidemiology of malaria in the forest-savanna transitional zone of Ghana. Malar J. 2009;8:220.

11. Owusu-Agyei S, Nettey OEA, Zandoh C, Sulemana A, Adda R, AmengaEtego $S$ et al. Demographic patterns and trends in Central Ghana: baseline indicators from the Kintampo Health and Demographic Surveillance System. Global Health Action. 2012;5:1-11.

12. Asante KP, Abokyi L, Zandoh C, Owusu R, Awini E, Sulemana A, et al. Community perceptions of malaria and malaria treatment behaviour in a rural district of Ghana: implications for artemisinin combination therapy. BMC Public Health. 2010;10:409.

13. Ajayi IO, Browne EN, Garshong B, Bateganya F, Yusuf B, Agyei-Baffour $P$, et al. Feasibility and acceptability of artemisinin-based combination therapy for the home management of malaria in four African sites. Malar J. 2008;7:6.

14. Justine UO, Nathaniel EO, Anslem UU, Maryrose OE, Dozie I. Knowledge, attitudes and perception of artemisinin-based combination therapy in malaria treatment in Yenagoa, Bayelsa state, Nigeria. Nat Sci. 2014;12:55-60.

15. Ewing VL, Terlouw DJ, Kapinda A, Pace C, Richards E, Tolhurst R, et al. Perceptions and utilization of the anti-malarials artemether-lumefantrine and dihydroartemisinin-piperaquine in young children in the Chikhwawa District of Malawi: a mixed methods study. Malar J. 2015;14:13.

16. Jegede AS. What led to the Nigerian boycott of the polio vaccination campaign? PLoS Med. 2007;4:e73.

17. Dial NJ, Ceesay SJ, Gosling RD, D'Alessandro U, Baltzell KA. A qualitative study to assess community barriers to malaria mass drug administration trials in the Gambia. Malar J. 2014;13:47.

18. Chatio S, Aborigo R, Adongo PB, Anyorigiya T, Akweongo P, Oduro A Adherence and uptake of artemisinin-based combination treatments for uncomplicated malaria: a qualitative study in Northern Ghana. PLoS One. 2015;10:e0116856.

19. Kamat VR, Nyato DJ. Community response to artemisinin-based combination therapy for childhood malaria: a case study from Dar es Salaam, Tanzania. Malar J. 2010;9:61.

20. Jorim RY, Korape S, Legu W, Koch M, Barrows LR. Matainaho TK; et al : An ethnobotanical survey of medicinal plants used in the eastern highlands of Papua New Guinea. J Ethnobiol Ethnomed. 2012;8:1-17.

21. Lamorde M, Tabuti JR, Obua C, Kukunda-Byobona C, Lanyero H, ByakikaKibwika $\mathrm{P}$, et al. Medicinal plants used by traditional medicine practitioners for the treatment of HIV/AIDS and related conditions in Uganda. J Ethnopharmacol. 2010;130:43-53.

22. Mahmood A, Mahmood A, Malik RN. Corrigendum to "Indigenous knowledge of medicinal plants from Leepa Valley, Azad Jammu and Kashmir, Pakistan". J Ethnopharmacol. 2012;143:338-46.

23. Odhiambo JA, Lukhoba CW, Dossaji SF. Evaluation of herbs as potential drugs/medicines. Afr J Tradit Complement Altern Med. 2011; 8. 
24. Stangeland T, Alele PE, Katuura E, Lye KA. Plants used to treat malaria in Nyakayojo sub-county, western Uganda. J Ethnopharmacol. 2011;137:154-66

25. Asase A, Akwetey GA, Achel DG. Ethnopharmacological use of herbal remedies for the treatment of malaria in the Dangme West District of Ghana. J Ethnopharmacol. 2010;129:367-76.

26. Buabeng KO, Duwiejua M, Dodoo AN, Matowe LK, Enlun DH. Selfreported use of anti-malarial drugs and health facility management of malaria in Ghana. MalarJ. 2007;6:85.

27. Chipwaza B, Mugasa JP, Mayumana I, Amuri M, Makungu C, Gwakisa PS. Self-medication with anti-malarials is a common practice in rural communities of Kilosa district in Tanzania despite the reported decline of malaria. Malar J. 2014;13:1

28. Deressa W, Ali A, Enqusellassie F. Self-treatment of malaria in rural communities, Butajira, southern Ethiopia. Bull World Health Organ. 2003;81:261-8.
29. Ezenduka CC, Ogbonna BO, Ekwunife OI, Okonta MJ, Esimone CO. Drugs use pattern for uncomplicated malaria in medicine retail outlets in Enugu urban, southeast Nigeria: implications for malaria treatment policy. Malar J. $2014 ; 13: 243$

30. Kimoloi S, Nicky O, Ondigo B, Langat B. Choice and sources of antimalarial drugs used for self-medication in Kisumu, Western Kenya. Afr J Pharm Ther. 2013;2:124-9.

31. Omole $\mathrm{M}$, Onademuren $\mathrm{O}$. A survey of antimalarial drug use practices among urban dwellers in Abeokuta, Nigeria. Afr J Biomed Res. 2013;13:1-7.

32. Musyoka LW. Treatment seeking for malaria in Mwea Division, Kirinyaga District, Kenya. Kenya: University of Nairobi Digital Repository; 2003.

33. WHO: Guidelines for the treatment of malaria. Geneva: World Health Organization; 2015

34. Willis-Shattuck M, Bidwell P, Thomas S, Wyness L, Blaauw D, Ditlopo P. Motivation and retention of health workers in developing countries: a systematic review. BMC Health Serv Res. 2008;8:247.

\section{Submit your next manuscript to BioMed Central and we will help you at every step:}

- We accept pre-submission inquiries

- Our selector tool helps you to find the most relevant journal

- We provide round the clock customer support

- Convenient online submission

- Thorough peer review

- Inclusion in PubMed and all major indexing services

- Maximum visibility for your research

Submit your manuscript at www.biomedcentral.com/submit
() Biomed Central 